\title{
Evolutionary history of lungfishes with a new phylogeny of post-Devonian genera
}

\author{
Anne Kemp ${ }^{1}$, Lionel Cavin ${ }^{2}$, Guillaume Guinot ${ }^{3}$
}

${ }^{1}$ Environmental Futures Centre, Griffith University, 170 Kessels Road, Nathan, Brisbane, QLD 4111, Australia; e-mail: a.kemp@griffith.edu.au

${ }^{2}$ Muséum d'histoire naturelle de la Ville de Genève, CP6434, 1211 Geneva 8, Switzerland; email: lionel.cavin@ville-ge.ch

${ }^{3}$ ISEM, UMR CNRS 5554, Université Montpellier 2, CC064, Place Eugène Bataillon, 34095 Montpellier Cedex 5, France ; E-mail : guillaume.guinot@umontpellier.fr

\section{Corresponding author: Anne Kemp}




\begin{abstract}
Several attempts to include post-Devonian lungfish in phylogenies of dipnoans have been made, but are hampered by the poor preservation of most Mesozoic and Cenozoic lungfish, and by the paucity of the occurrences of these taxa. This contribution has made use of the few post-Devonian fossils that are known from cranial, dental and post-cranial remains, to compare them with Devonian material and with living lungfish. Characters have been chosen to cover the best-preserved structures of the Mesozoic and Cenozoic fossils, and the resulting phylogeny has been discussed in relation to previous analyses. The post-Devonian phylogeny has been anchored to a published phylogeny of Devonian taxa and a phylogenetic diversity curve has been computed. Based on this phylogeny rates of origination and extinction have been calculated, and environmental transfers and trends in body size changes have been detected. Our analyses show that the Permian gnathorhizodontids and the extant lepidosirenids are closely related, that lungfishes have experienced two phases of taxic diversification, a marine one in the Devonian and a freshwater one in the Permian. Major negative size shifts occurred during the marine phase and major positive size shifts occurred during the freshwater phase. A new classification of post-Devonian dipnoan families is also presented.
\end{abstract}

Keywords: Dipnoi; Phylogeny; Taxic diversity; Body size; Palaeoenvironment

\title{
1. Introduction
}

Dipnoi, or lungfishes, are one of the three extant sarcopterygian clades. Their fossil record starts in the Early Devonian and diversified during this time interval. After the end-Devonian mass extinction, lungfish diversity was supposedly low during the Early Carboniferous. During the Late Carboniferous onwards, the taxonomic diversity remains low, less than 25 species by epoch or period (Schultze, 2004), until the present time, with 3 genera and 6 species. There is a general agreement to regard lungfishes as freshwater organisms since the Late Carboniferous, although some occurrences may come from nearshore environments (Schultze, 1985; McCahon and Miller, 2015).

Previous phylogenetic analyses of lungfishes concentrate on Devonian forms, with the occasional attempt to include post-Palaeozoic material (Schultze and Chorn, 1997; Pardo et 
al., 2014). Here, we propose a phylogenetic analysis of post-Devonian lungfishes, including some Carboniferous and Permian forms, on the basis of a new set of morphological characters. These characters can be assessed on most of the specimens, and discriminate mostly the post-Palaeozoic genera. The phylogenetic diversity of the group is assessed by anchoring our post-Palaeozoic phylogeny on a published Palaeozoic phylogeny (Pardo et al., 2014). In addition, we analyse the evolution of body size and potential shifts between environments during the evolutionary history of the group.

The phylogeny is presented as a working hypothesis, not a final analysis, and it is intended to aid understanding of post-Palaeozoic lungfishes, not Devonian species. We have explained our choice of the taxa considered, and tried to avoid swathes of missing data. Our phylogeny was never intended to "sort out" the Palaeozoic genera. We tried to analyse the post-Devonian taxa, most ignored by previous workers, and work out a possible comparison with some early genera. Inclusion of many Devonian genera, most of which we have not seen and many of which should be synonymised, was not our intention.

\section{Materials and methods}

\subsection{Phylogenetic analysis}

\subsubsection{Choice of terminal taxa for the post-Devonian phylogeny}

The characters are based on genera, not species, which is regarded as the more appropriate taxonomical rank for estimating diversity based on extinct taxa (Forey et al., 2004). The only Devonian genera included in the analysis are Chirodipterus and Dipterus used as outgroup. The most completely understood of the Carboniferous, Permian, Mesozoic and Cenozoic genera have been selected. Usually only one species of the genus is used, sometimes more than one if they are close. The species chosen is generally the type species. Terminal taxa with additional data are listed in Supplementary Data 1.

Post-Palaeozoic lungfishes are usually known by incomplete material and previous phylogenetic studies were based on data matrices that are full of question marks. In this study, we decided to select only well-known taxa, genera for which tooth plates, cranial and postcranial elements are known. As can be seen in our data matrix, few question marks are present. The idea beyond this decision is that the obtained phylogeny would be robust and could serve as a backbone for future studies. It is true that the resulting phylogeny is actually 
not very strongly supported, but its topology is, at least, not undermined by the distribution of question marks.

Some taxa were excluded from the analysis because extant fossil remains are incomplete or interpretation of the material is disputed. Namatozodia is a hatchling, probably $5 \mathrm{~cm}$ long, known from a partial skull roof and nothing else. The character list for this genus would have been almost entirely made up of question marks. Ariguna is a juvenile, and the pattern of the skull bones is disputed (Kemp 1994; Schultze 2004). The dentition is unknown and many cranial and post-cranial characters cannot be determined with any accuracy. Aphelodus is a composite of isolated bones. Straitonia has no tooth plates. Delatitia is described on two specimens found years apart, not even associated at the time of discovery. Potamoceratodus adds nothing to our knowledge of Ceratodus. Melanognathus is, like Uranolophus, not close enough to derived dipnoans to be included as a comparison.

The character list (Supplementary Data-2) is based on features present in post-Palaeozoic genera that have both cranial and postcranial features preserved, as well as tooth plates, and can be related back to Devonian taxa. Characters were chosen to cover structures that were actually present in every taxon to avoid as far as possible the use of question marks, and to have responses of present/absent. Character states are illustrated for some genera in figure 1.

A major problem arises from the similarities that can be traced throughout the group. Major structural features such as the shapes of pectoral and pelvic fins, details of the scales, and the shapes of the head and jaws are often similar. A further problem arises from preservation. Most Devonian genera can be characterised on details of the skull structure and often on the dentition and postcranial morphology. This information may be deficient for Mesozoic and Cenozoic genera, and many are known only from tooth plates, although genera known only from tooth plates were not used in the analysis, such as Metaceratodus. Evidence derived from living lungfish is more complete. A further difficulty arises from the original descriptions of Devonian genera, and a tendency to erect a new taxon every time a new specimen is found, although it may in fact belong to an existing genus. This has contributed to the large number of Devonian genera and to fine distinctions in potential ages and environments. This has not happened so much in the post-Palaeozoic material used in this analysis, because of the rarity of appropriately preserved specimens. However, it does mean that the age range and the possible environments occupied by the genus appears to be a lot wider in Mesozoic and Cenozoic taxa than it is in Devonian genera. In the living lungfishes, potential environments could be rivers or wetlands of a range of water qualities, and this is 
also the case with some of the Cenozoic genera, particularly in Australia where the geology of many Cenozoic environments is well known (Callen and Tedford, 1976).

The high incidence of anomalous structures in the skull roofing bone patterns of early genera means that a detailed analysis of the bones in relation to each other is not possible or appropriate, for example in species represented by a few fossils such as Barwickia (Long, 1992). Patterns of fusion and loss often have to be estimated in the fossils. This is easy enough to work out with Neoceratodus, and in related genera, as well as the lepidosirenids, in which the major bones are equivalent, but creates difficulties when comparing for example,

\section{Ceratodus and Ptychoceratodus.}

Most of the characters have been assessed on the actual specimens, and occasionally from the literature. Details of skull bone labels are avoided, as these are not universally accepted.

\subsection{Phylogenetic diversity}

Taxic diversities provided by a direct reading of the fossil record (number of taxa per timebins) are unreliable because they include shortcomings related to preservation and sampling biases. Phylogenetic diversities can correct observed taxic diversities by constraining the fossil record of taxa to comply with a tree topology as two sister taxa must have the same First Appearance Datum (FAD). Congruence between tree topology and observed ages of FAD is made by the addition of ghost ranges, which are artificial stratigraphic ranges that fill in gaps in the fossil record according to the phylogeny. Although these methods were initially used to compute congruence scores that reflect the quality of the fossil record and/or the stratigraphic fit of competing phylogenies (Pol et al., 2004; Pol and Norell, 2006 for a review), they provide computed FADs that can be used to estimate phylogenetic diversities. Congruence methods rely on two sets of data (phylogeny and fossil record) that may include uncertainties (polytomies and age of FADs, respectively). The Comprehensive Polytomy (ComPoly) approach of Boyd et al. (2011) is a congruence-testing method that considers these uncertainties. This approach provides a range of computed FADs by two methods for treating polytomies. The Chronological method resolves (restructures) polytomies in pectinate arrangement with the taxa having the oldest FAD being at the base of the resolved clade in order to maximize fit to stratigraphy (Siddall, 1998; Pol and Norell, 2001). Conversely, the Reverse-Chronological method resolves the polytomies in pectinate arrangement with the taxa having the youngest FAD being at the base of the resolved clade to minimize fit to stratigraphy (Wills, 1999). The ComPoly approach also accounts for uncertainties in the age 
of FADs, which is commonly represented by one or a range of chronostratigraphic units in observed data (e.g. a stage or a group of stages). This is addressed by performing replicates where FAD ages of each terminal taxon are randomly picked within the age range of observed FADs for each replicate (see Pol and Norell, 2006). This provides a range of corresponding computed FADs for each method (Chronological and Reverse-Chronological). Hence, each restructuring method provides a range of congruence scores that consider uncertainties in the age of first occurrence. Combining scores (lowest score using the Reverse-Chronological method and highest score using the Chronological method) therefore takes into account uncertainties in both datasets (fossil record and phylogeny) in providing a total range of the possible variation implied by the data. This method was applied here using the ASCC software version 4.0.7 with 1000000 replicates for FADs.

In order to cover the whole evolutionary history of Dipnoi, our post-Devonian phylogeny was anchored in the recent phylogeny of Palaeozoic taxa provided by Pardo et al. (2014), which is built on a set of characters, whose definition and scoring are in better agreement with the opinions of one of us (AK).

Phylogenetic diversities were then calculated on the basis of computed FADs and observed Last Appearance Data (LADs). As for the FADs, some of the taxa considered here have their LADs represented by a range of stages. In order to cover the whole variation of possible diversity pattern implied by the data, phylogenetic diversities were computed using both minimum and maximum LAD values. We computed per capita origination and extinction rates using the calculation of Foote (2000).

\subsection{Environment and body size}

We gathered data on environment distribution and body size with the aim of using our time-calibrated phylogeny to reconstruct the evolution of these parameters throughout the evolutionary history of lungfishes. Environment was coded as a discrete variable with three states: marine (1), freshwater (2) and mixed (3), the latter representing brackish environments or genera occurring in both marine and freshwaters. We coded each terminal taxon with a single character state according to their observed distribution (for modern taxa) or to the palaeoenvironmental data present in the literature (for fossil taxa). We then reconstructed the ancestral states using maximum likelihood with the function ace of the R-package 'ape' (Paradis et al., 2004) Analyses were run using three different models: 1) all transition rates are different (ARD), 2) transition rates are symmetrical (SYM), where the transition rate from 
environment 1 to 2 equals that from environment 2 to 1, and 3) all transition rates are equal (ER). Model fits were then computed using the Akaike Information Criterion (AIC).

Body size data correspond to the maximum body length from snout to posterior extremity of caudal fin, for both recent and fossil taxa. These values were collected from the literature for each terminal taxon (fossil and extant). Ancestral body length reconstruction was performed using Maximum Likelihood ancestral state reconstruction provided by the fastAnc function of the R-package 'phytools' (Revell, 2012).

\section{Results}

\subsection{Characters and character definitions}

Characters and character definitions are listed in Supplementary Data 2. Coding of characters is presented in Table 1.

\subsection{Phylogenetic analysis}

We ran the analysis using PAUP 4.0b10 (Swofford, 2001) heuristic search option, random addition sequence, replicated 10,000 times, 10 trees held at each iteration, and tree bisection and reconnection branch swapping. We obtained a single most parsimonious tree (154 steps, $\mathrm{CI}=0.5359, \mathrm{RI}=0.6773$ ) (Fig. 2). The node supporting all post-Devonian genera is well supported (Bremer Index $(\mathrm{BI}) \geq 5$, Bootstrap value $(\mathrm{BV})=100)$ by fifteen characters, seven of them being uniquely derived. Ctenodus is the basal most post-Devonian genus. The node grouping Sagenodus and the more derived genera is well supported $(\mathrm{BI}=3, \mathrm{BV}=97)$ by four characters, two of them uniquely derived and unambiguous (Character numbers in square brackets refer to character traits as listed in Supplementary Data 2) [8]: the D bone is fused with other bones and; [56]: there is a pulp cavity below the tooth tissue). More derived genera than Sagenodus are gathered by a well supported node $(\mathrm{BI}=4, \mathrm{BV}=100)$, characterized by seven characters, four of them being uniquely derived ([1]: the skull roof has fusion or loss of bones [unambiguous], [4]: the snout has no separate rostral bones [unambiguous], [18]: there is an ascending pterygopalatine process, and [27]: there is no gular bone). The clade Uronemus + Conchopoma, which is the sister-group to all more derived genera, is rather well supported $(\mathrm{BI}=2, \mathrm{BV}=84)$, although the five characters supporting the node are homoplastic (see Section 4.1.2.). The node gathering the other genera (Paraceratodus and more derived 
genera) is well supported $(\mathrm{BI}=3, \mathrm{BV}=99)$ and characterized by seven characters, three uniquely derived and unambiguous ([6]: the EQ or equivalent bone is single, [11]: the lateral series of skull ossifications has two bones or fewer and, [21]: the sensory line canals are superficial). More derived genera (Ferganoceratodus and all others) are gathered by a rather well supported node (BI = 3, VI = 100) supported by four homoplasies ([9], [10], [12], [58]). The next node supports the crown Dipnoi, with the Neoceratodus lineage on one side and the Protopterus-Lepidosiren on the other. Unfortunately, this node is not strongly supported and characterized by three characters only, one being uniquely derived and unambiguous ([69]: The lymphatic vessels in snout are not ossified). The clade Mioceratodus and Neoceratodus, which represents here the Neoceratodus lineage, is well supported $(\mathrm{BI}=3, \mathrm{BV}=97)$ by five characters, one being uniquely derived and unambiguous ([54]: a posterior heel on tooth plate is present). The Protopterus-Lepidosiren lineage, represented here by Ceratodus and the more derived members of this clade, is weakly supported by five characters, two being uniquely derived and unambiguous ([13]: XK or equivalent bone not separate or absent and, [33]: posterior shaft of parasphenoid is structured). The next node, grouping Ptychoceratodus and Gosfordia on one side and the other genera of the Protopterus-Lepidosiren lineage on the other, is also weakly supported by six homoplasies ([39], [42], [45], [60], [65], [67]). Ptychoceratodus and Gosfordia are grouped together by four homoplasies ([12], [28], [38], [55]). The other genera of this clade, which consists of the disputed Gnathorhizalepidosirenid relationship (see Section 4.1.3), are supported by a moderately strong node (BV $=53$ ) characterized by six character changes, one being uniquely derived and unambiguous ([74]: fish able to make aestivation burrow). Persephonichthys and Gnathorhiza are closely related genera as indicated by the strongly supported node $(\mathrm{BI} \geq 5, \mathrm{BV}=100)$, characterized by ten characters, one uniquely derived and unambiguous ([53]: Cusps on last ridge compressed laterally, in line with ridge). Eventually, Lepidosiren and Protopterus form a strong clade $(\mathrm{BI} \geq 5, \mathrm{BV}=100)$ defined by eleven characters, three being uniquely derived and unambiguous ([34]: anterior end of the parasphenoid has a vacuity, [46]: gap between lower jaw bones is absent, [61]: there is no hyoid process and no basihyal to support a tongue).

\subsection{Phylogenetic diversity}

The phylogeny of Pardo et al. (2014) and ours have four clades in common: Sagenodus, Persephonichthys, Neoceratodus, and "Lepidosireniformes" (including Lepidosiren and 
Protopterus). In the tree presented by Pardo et al. (2014), Sagenodus is located in a clade comprising Fleurantia, Barwickia, and Howidipterus, among others. This topology is not in contradiction with our results. In our phylogeny, Ctenodus is located between Chirodipterus (C. australis) and Sagenodus. Ctenodus is not included in Pardo et al.'s phylogeny and consequently we have no way to locate it in our compound phylogeny, because Sagenodus is related to the crown-group. We could either consider Ctenodus and place all the uncertain genera in a polytomy (10 genera) or withdraw Ctenodus from the compound phylogeny. We chose the second solution. The rest of our post-Devonian tree, i.e. genera more derived than Sagenodus, corresponds to a clade situated as the sister group of 'Rhinodipterus' kimberleyensis in Pardo et al.'s phylogeny, and which contains (Persephonichthys, (Neoceratodus, Lepidosireniformes)). The topology of the latter clade, however, is not retrieved in our phylogeny (Persephonichthys forms, together with Gnathorhiza, the sister group of Lepidosireniformes). For this clade, we use the topology obtained above, which rests on more terminal taxa and on a set of well-suited characters for the compared taxa.

The composite phylogeny used for phylogenetic diversity estimates (Fig. 3A) comprises two polytomies: one in the ingroup involving Tarachomylax and Megalognathus and a second one involving the two taxa forming the outgroup (Youngolepis and Psarolepis).

Tarachomylax and Megalognathus have the same FAD and LAD and hence, the resolution of this clade in chronological or reverse chronological order does not impact the amount of ghost lineage in the tree. Consequently, differences between the Chronological and ReverseChronological tree data only rest on the resolution of the outgroup polytomy. This is represented by the strong overlap of congruence scores representing each method for polytomy resolution (see Supplementary Data 3). Congruence scores for the ComPoly approach still show a range of variation that is therefore not attributable to tree topologies but to uncertainties in FADs. Because outgroup taxa are not considered in phylogenetic diversity estimates, ranges of computed FADs resulting from the Chronological and ReverseChronological methods are similar. We thus selected four phylogenetic diversity estimates using the computed FADs of the most- and least-congruent datasets (FADmax and FADmin, respectively) combined with the maximum (LADmax) and minimum (LADmin) ages of last occurrence, when applicable, in order to cover the total variation implied by the data. These include: 1) FADmax-LADmin; 2) FADmax-LADmax; 3) FADmin-LADmax; 4) FADminLADmin.

Resulting phylogenetic palaeodiversity patterns and corresponding per capita origination and extinction rates are shown in Figure $3 \mathrm{~B}$ and $3 \mathrm{C}$, respectively. The Lower Devonian is 
marked by a rapid diversity increase that led to the highest values of taxic richness of the evolutionary history of Dipnoi in the Middle-Upper Devonian. The Devonian as a whole is characterized by high turnover rates as well as by well-constrained stratigraphic ranges of taxa, which result in the absence of uncertainty in the pattern observed. A first diversity decrease initiated in the Famennian and lasted in the lowermost Carboniferous (Tournaisian). From the Carboniferous onwards, diversity patterns vary according to stratigraphic uncertainties. Whatsoever, the Carboniferous appears as a period of low maximum diversity and the range values of phylogenetic diversity observed for this period is due to the lack of accurate data on the FADs of Sagenodus and Uronemus. The Permian is characterized by a diversity increase linked with the diversification of crown dipnoans based on the computed phylogeny, although the fossil record of this clade is very poor in this time interval. The exact timing of this diversification is however unclear and is mainly related to the uncertain FADs of Gnathoriza and Persephonichthys, but our data indicate that this event took place in the Lower Permian (Cisuralian). Post-Cisuralian diversity decreases until the Cretaceous with the exception of a minor increase in the Lower Triassic (Gosfordia+Ptychoceratodus). A slight increase occurred in the Lower Cretaceous with the appearance of modern genera. After this time, lungfish history is affected only by the last occurrence of Ceratodus (Mid-Cretaceous) and Mioceratodus (Pliocene).

\subsection{Environment and body size shifts}

Results of ancestral habitat reconstruction based on the ER model show the best fit (see AIC scores Supplementary Data 4) and were selected for further analyses, although other models gave similar results. Under this model, all nodes were given robust posterior probabilities above 0.8. Results indicate a marine ancestry for Dipnoi and dominance of marine habitat for Devonian clades (Fig. 4). Three colonization events of freshwater habitats by primarily marine clades occurred in lungfish evolutionary history. The first occurred in the Middle Devonian and concerns the colonization of continental aquatic settings by the fleurantiids (sensu Long, 1993). Fleurantia then shifted back to the marine realm in the Middle Devonian, which represents the only habitat colonization in this direction (freshwater to marine). Another colonization of freshwater environments took place in the Lower Carboniferous with Conchopoma, which shares a marine ancestry with Uronemus (but see discussion in Section 4.1.2). The third colonization event of freshwaters occurred in the 
Carboniferous-Lower Permian interval and involves the clade Ceratodontoidei as defined in Section 5 .

Ancestral body size reconstructions allowed the identification of the age and distribution of size shifts (Fig. 4). Major positive and negative shifts in size were identified by selecting values lying above and below the upper and lower whiskers, respectively, of the box-andwhisker plot performed on all size shifts over the tree. Results indicate that the top 6 biggest positive size shifts (including the three major shifts) occurred in freshwater environments. With the exception of Sagenodus, these positive shifts occurred in the Ceratodontoidei and mainly in the Mesozoic. Conversely, 7 out of the 8 biggest negative shifts in size (5 out of the 6 major negative shifts) occurred in the Devonian marine realms, the only exception being Persephonichthys (freshwater). More generally, there is an equal proportion of positive and negative shifts in size in the marine and freshwater realms (Supplementary Data 5). However, major positive shifts occurred mainly in the freshwater environments whereas major negative shifts predominantly occurred in the marine realm. Environment shifts are scarce in the evolutionary history of lungfishes (see above) but freshwater colonizations by primarily marine taxa are generally linked with a size increase whereas the single colonization of marine habitat by a primarily freshwater taxon coincides with a size reduction.

\section{Discussion}

\subsection{Phylogeny}

The occurrence of Sagenodus as a representative of a post-Devonian clade distinct from the crown-group, and the occurrence of 'Rhinodipterus' kimberleyensis and Orlovichthys as successive sister-groups to the crown group are two results directly borrowed from the analysis of Pardo et al. (2014). Consequently, they are not discussed here.

\subsection{1. 'Modern' lungfishes}

The node defining the 'modern' lungfishes groups Uronemus - Conchopoma and more derived taxa. Reason for this choice is twofold: 1) the uncertain position of Ctenodus between our phylogeny and Pardo et al.'s phylogeny and the location of Sagenodus in a separate clade in Pardo et al.'s phylogeny, and 2) the strong support of this node in our phylogenetic analysis (Section 3.1). 


\subsubsection{Uronemus - Conchopoma}

Schultze (1975) noticed that Conchopoma possesses a mixture of primitive dental characters and derived cranial characters. Smith et al. (1987) rejected a direct relationship between Uronemus and Conchopoma. Marshall (1988) considered Conchopoma as closer to the denticle-shedding lungfishes, such as Uranolophus and Griphognathus, than to the lungfishes with dental plates. Kemp (2001a) pointed out that both Conchopoma and Uronemus are separated from other derived lungfishes, the latter by retaining traces of a radiating pattern and the former by being denticulate. Both genera have been placed in different positions in phylogenetic analyses. Campbell and Barwick (1990) found Uronemus close to Gnathorhiza and Monogahela, but Conchopoma rooted in a Devonian group (including Holodipterus). Schultze and Marshall (1993) resolved Conchopoma as the sistergroup of Gnathorhiza and more derived genera, as in the present study, but Uronemus is located in a more basal position, before Sagenodus.

In our analysis, Conchopoma and Uronemus are sister genera, both forming the sister group of post-Carboniferous lungfishes. This topology should be regarded with caution because it rests on the analyses of characters of post-Devonian taxa only. It is possible that characters impacting on the topology of Palaeozoic taxa originally used in the analysis of Pardo et al. (2014), but not used in our own analysis, would have modified the topology of these 'transitional' forms. Keeping this point in mind, it is interesting to look at the characters supporting the Conchopoma - Uronemus clade. As mentioned above, the four character changes supporting the clade are homoplastic and one is a unique reversion, [26] the presence of splenial and postsplenial on the anterior mandible. Another one is also a reversion, [30] a contact between the parasphenoid and the pterygopalatine, but this one also occurred independently in Ceratodus. Two character changes, [35] partially mineralized chondrocranium, and [67] reduced scale cover, are homoplastic and ambiguous and the last one, [38] ridge origin posterior, cannot be coded for both genera.

Examination of the character changes supporting this clade shows that it is poorly supported by characters.

\subsubsection{Gnathorhiza as a lepidosirenid?}

Stromer (1910) was the first author to notice similarities between tooth plates of Gnathorhiza ("Sagenodus") pertenuis and lepidosirenids, in particular the occurrence of sharp ridges. However, he pointed out differences between both taxa, such as the occurrence of denticles on the ridges and the presence of a fourth ridge on the upper plates. He regarded 
these similarities as convergent. Romer and Smith (1934) regarded the difference between both genera pointed out by Stromer as not significant and considered the condition in Gnathorhiza as intermediate between a dipterid state and a lepidosirenid state. They included Gnathorhiza in the family Lepidosirenidae. Olson (1951) and Olson and Daly (1972) retain this familial assignment, although Olson (1951) conceded that 'there is no way of settling this matter from the evidence now available'. In this study, Olson described for the first time cranial remains of Gnathoriza. Based on this new evidence, he suggested a close relationship between Sagenodus and Gnathorhiza (the latter 'could have been derived' from the former). He also noticed that cranial characters of Gnathorhiza share features or trends with lepidosirenids. These trends led to the disappearance of the thin D and $\mathrm{J}$ bones, as well as of the I bone, the B bone and those from the lateral series would have sunk deeper below the surface, while the bones from the mediolateral series would have stayed superficial but extended posteriorly. Carlson (1968) also suggested a direct relationship between Gnathorhiza and lepidosirenids on the basis of the arguments pointed out by Olson, but also on new lines of evidence, such as ontogeny (with embryological data from Holmgren (1949)) and on the supposed aestivation ability due to the discovery of specimens within burrows more than a decade before (Romer and Olson, 1954). Then Dalquest (1968) and Dalquest et al. (1989) studied post-cranial material of Gnathorhiza from the Permian of Texas. The body is described as eel-like, 'not unlike that of the modern South American Lepidosiren', although the head was proportionally larger. Differences noticed with lepidosirenids also are the pleural ribs, which were relatively larger and stouter than those of modem lungfishes and the abbreviated, pedunculate tail, which was possibly related to the tail-down position observed in aestivation burrows. The hypothesis of Gnathorhiza as a stem lepidosirenid was disputed by Stromer (1938), and then by Berman (1968), who questioned the shared dental characters. Gnathorhiza is considered to be herbivorous while lepidosirenids are carnivorous, but this may not be entirely true. The latter also pointed out that no aestivation burrows are known in the fossil record between the Lower Permian and the Recent. Gnathorhiza (Skrzycki 1916) has also been considered. Since then, however, lungfish burrows have been described from the Late Triassic (Gobetz et al., 2006) and Late Cretaceous (Orsulak et al., 2007) of USA, from the Early Cretaceous of Denmark (Surlyk et al., 2008), and from the Late Cretaceous of Madagascar (Marshall and Rogers, 2012 ). Another criticism of the Gnathorhizalepidosirenids connection pointed out by Denison (1974) is that no petrodentine is present in Gnathorhiza tooth plates unlike lepidosirenid plates, an argument reused by Berman (1976). In most subsequent studies, the Gnathorhiza - lepidosirenid affinities was dismissed 
(Marshall, 1986; Schultze, 1992; Schultze and Marshall, 1993; Schultze, 2004). In fact, Gnathorhiza does have petrodentine sensu Lison (Lison, 1941; Kemp, 2001b).

We do not have large numbers of specimens of Persephonichthys, unless the very similar material of Monongahela is included. We have one example of Persephonichthys, enclosed in a burrow.

Gnathorhiza and lepidosirenids can be linked on skull characters and body form (stout, heavily ossified) and on characters of the tooth plates (true petrodentine, small number of ridges) and bones of the jaws. Schultze (2009) is incorrect on Lepidosiren - the older literature Kerr, 1950) indicates that they can aestivate. We only say "capable of aestivation".

Tranodis was not included in the analysis. The taxon is not reported from numerous estivation burrows, and the morphological remains are poor. This is a working hypothesis. Excluding aestivation as a character would be akin to forgetting an important fact. It should be pointed out here that aestivation is the only unambiguous character, which supports the node, but other homoplastic characters are also present there. Most nodes in the tree are supported by a majority of homoplastic characters.

It is true that the gnathorhizid-lepidosirenid relationship is not strongly supported. This is why we discuss this point in length. There are arguments other than just the value of the support of the node. The evidence supporting this relationship is still weak, but other homoplastic characters are also present there. Most nodes in the tree are supported by a majority of homoplastic characters.

Through this short historical review, it is noteworthy that a connection of Gnathorhiza with extant lepidosirenids was first proposed on the basis of tooth plates only, was then supported by cranial and post-cranial features after the discovery of new material, and finally reinforced by the discovery of aestivation burrows. This series of assumptions, based on a succession of independent emerging evidence, is not a validation of the hypothesis per se, but is an interesting case of consilience.

As shown above, the sister-group relationships between Gnathorhiza + Persephonichthys and the lepidosirenids is weakly supported by a single unambiguous character, which is furthermore one of the more uncertain character to code, except for Recent genera and Gnathorhiza (aestivation burrows). Among the other character changes, two are homoplastic with Neoceratodus only: [5] the EQ or equivalent bone has a long anterior process, and [17] a descending process is present on the medial bone. The other character changes are homoplastic with other clades: [35] chondrocranium partially mineralized (with a possible reversion in Gnathorhiza although this character state is rarely observable in fossil forms) 
with the clade Uronemus + Conchopoma, [47] presence of petrodentine in Mioceratodus, and [51] cusp on ridge 1 recurved in Chirodipterus.

Finally, it can be mentioned that the state of preservation of the Gnathorhiza material is not good enough for coding paired fins character in our analysis. However, Dalquest et al. (1989) did not find evidence of paddle-shaped paired fins and concluded that this genus had probably slender and tentacle-like paired fin similar to those of Lepidosiren.

The support of the sister-group relationship between gnathorhizids and lepidosirenids topology is still weak, but this hypothesis is regarded here as the most likely. A consequence of this topology is the deep split, before the Permian, between gnathorhizids and lepidosirenids, and as a consequence a deep split between the living lepidosirenids and neoceratodontids. Such a deep split between both living clades has a consequence on the evolutionary distinctiveness of the Australian lungfish, which is still higher than previously calculated (Cavin and Kemp, 2011).

\subsection{Phylogenetic diversity estimates}

The difference between observed and computed curves rests on the new typology of postDevonian genera, in particular the Gnathorhiza - Persephonichthys clade as sister group to the lepidosirenids, and the following Early Permian split between this clade and the Neoceratodus lineage. If true, this result indicates that the fossil record of the Neoceratodus lineage and of the stem lepidosirenids (sensu the definition in Section 5) remains largely to be discovered (or to be or properly recognized in the available material) in the Permian and Triassic (both periods for which the discrepancy between observed and computed curves are the largest).

The low taxic diversity of the Carboniferous, and in particular the Romer's Gap in the Early Carboniferous (Coates and Clack, 1995), is probably largely due to the quality of the fossil record of that time interval. Recently, Sharp and Clack (2013) reviewed the material of Ctenodus from the United Kingdom and showed that the genus crossed the Lower-Upper Carboniferous boundary. Later, Smithson et al. (2016) described a diverse lungfish assemblage from the Tournaisian of northern Britain, which partly filled the Romer's gap for this group. The assemblage contains new species of Ctenodus alongside four new genera (Xylognathus, Ballagadus, Coccovedus, Occludus), all based on isolated tooth plates. Interestingly, the origination rate based on phylogenetic diversities shows a diversification in the Lower Carboniferous, corroborating the observation of Smithson et al., and this even 
while Ctenodus, which forms a significant part of the Tournaisian diversity, was removed from the computed phylogeny for reasons explained above.

In contrast to previously published diversity curves (Schultze, 2004), a high peak of taxic diversity occurred in the Permian and not in the Early Triassic. The high Permian taxic diversity computed here is largely due to the presence of ghost lineages. Conversely, several of the Early Triassic taxa described in the literature (e.g. Beltanodus, Microceratodus, Asiatoceratodus, Gosfordia, Namatozodia) are not considered here because they were not included in the phylogeny.

During the Cretaceous and Cenozoic, numerous species based on isolated tooth plates as well as some genera represented by more complete material (Retodus, Lavocatodus) were not included in the taxic diversity curves.

Thus, although the computation of taxic diversity takes into account preservational bias by including the occurrence of ghost lineages, it appears that the peculiar mode of preservation of lungfish material strongly affects the shape of the diversity curve. In particular, the record made of mostly of tooth plates after the Palaeozoic, but also in the Carboniferous, lowers significantly the level of the diversity curves. Some observations (Smithson et al., 2016) indicate that lungfishes diversified shortly after the end Devonian and the end Permian mass extinctions, although these events are not perceivable on our diversity curves. The dataset that we analyzed for habitat and body size shifts cover the whole period of lungfish history (Devonian to present).

Lloyd et al. (2012) have analysed rates of evolution in lungfish, based on several phylogenies that include post-Palaeozoic dipnoans, notably Schultze and Marshall (1993), and Schultze (2004) with some data from Schultze and Chorn (1997). A large number of genera have been described since the first two papers were published. Many of the characters in these papers cannot be assessed on Cenozoic and Mesozoic genera because the characters described are not present, such as those that pertain to the cheek region in Neoceratodus and Lepidosiren. The data presented by Schultze and Marshall (1993) are detailed, and many involve the positions of individual skull bones in relation to each other, although in more recent genera the bones are fused, missing or the determinations are uncertain. Similar objections can be raised to the dataset used by Schultze and Chorn (1997). In the cheek series of Neoceratodus, the infraorbital bones are large and close to each other (Kemp, 1998) but the ossicles of the mandibular series are small and isolated in soft tissue, and often absent, although both series are illustrated as large and separate in the Neoceratodus skull figured (Schultze 2004: fig. 6). Schultze 2004 claims that Mioceratodus anemosyrus had no XK bone 
in the skull roof, although the relevant part of the M. anemosyrus skull is not preserved and an XK bone may have been present (Kemp, 1992). The closely related species, Mioceratodus gregoryi, has a distinct XK bone (Kemp, 1998). He uses Namatozodia, a hatchling known from a partial skull roof, and Aphelodus, reconstructed from isolated skull and jaw bones. Both are unreliable. Ariguna formosa, a solitary juvenile specimen, may or may not have the skull bones he describes in his database. The pattern of skull bones is disputed (Kemp, 1994). The three papers that include significant post Palaeozoic genera all draw different conclusions about the relationships among the taxa, for instance, the position of Paraceratodus. Asiatoceratodus and Arganodus, widely separated in Schultze 2004, are so similar in skull bones and tooth plates that the two genera have been synonymised at least once (Kemp, 1998). It is possible that the analysis of Lloyd et al. (2012), based on data derived from the literature that may not be correct, is not reliable.

\subsection{Environment and body size shifts}

All major negative body size shifts concern marine Devonian clades with the exception of Persephonichthys, but specimens of this taxon could correspond to an advanced juvenile (Pardo et al., 2014). Conversely, all major positive body size shifts concern freshwater clades. The pattern observed in the marine environment is in sharp contrast with what happened for Mesozoic marine ray-finned fishes (Actinopterygii), for which a general body size increase is observed through time among most of the clades (Heim et al., 2015). It should be noted, however, that Uranolophus, the oldest lungfish, was exceptionally large, and that many of the specimens described from Devonian genera are definitely juvenile or subadult. Some chirodipterids were quite big too, although the one we are using was small. A finer analysis of the environment occupied by the Devonian marine lungfishes and of the evolution of their diet could help us to understand this surprising trend.

Except Conchopoma, both shifts to freshwater environment concern deep nodes. It is worth noting that the shift that occurred in the Devonian concerns a whole clade (except Fleurantia, which was marine), which was resolved on the basis of a morphological analysis (Pardo et al., 2014). Thus, information about habitats confirms previous results based on morphology. Long (1993) already found an almost similar clade, named the fleurantiids, on the basis of the presence of cranial ribs, but also based on other characters. This environmental shift occurred at a time of low global oxygen level, when a more basal marine lungfish (Rhinodipterus) is described as showing, for the first time, adaptation to air breathing (Clement and Long, 2010). 
However, the presence of cranial ribs does not indicate that a lungfish must have breathed air. Cranial ribs are common among dipnoans of all ages and habitats, and are more probably associated with suctorial actions of the jaws, specifically to assist feeding (Bemis, 1987). It is perfectly true that lungfish have one or more specialised systems in their jaw mechanics, collectively described as a buccal pump, to support a suctorial function of the jaws. Biologists (Bemis, 1987, Greenwood, 1987) are aware that the buccal pump has several functions. Air breathing is only one of them, and only sometimes. Long and his co-workers consider that the presence of a possible buccal pump means that lungfish breathed air. However, it is evident from the biological literature that lungfish draw air and water into the oral cavity, as well as food, and that they use suction to dig in mud and to build burrows (Greenwood, 1987). Most lungfish have cranial ribs and a buccal pump, but this does not mean that they breathed air. Juvenile Neoceratodus, too small to have developed cranial ribs, will rise to the surface of the water to gulp air. Most lungfish would not have breathed air, because they lived in deep water, or because they rely on an efficient set of gills. No amount of three dimensional analysis of fossil lungfish (Clement et al., 2016) explains what living or fossil lungfish can actually do, and the system does not relate only to drawing air into the oral cavity.

One of the freshwater fleurantiids, Sagenodus, shows the second major positive body size shift.

The second shift towards freshwaters occurred at the base of the ceratodontoids, although some sporadic returns to marine and brackish waters may have occurred subsequently. This clade includes most Permian and all post-Paleozoic forms (i.e. the crown-group minus Paraceratodus and Ferganoceratodus in our phylogeny). All major positive body size shifts (except one for Sagenodus) occurred in this clade. Some Cretaceous forms, not included in our analysis, reached giant sizes, such as Retodus in the Cretaceous of North Africa (Churcher et al., 2006)

The general size increase observed in the freshwater lineage of lungfishes contrasts with the size decrease in the older marine lineage and differs from what is observed in ray-finned fishes, whose freshwater clades show generally no constant trends through time.

\section{Systematic Paleontology}

In order to preserve as far as possible stability in the taxonomy, we propose below a stembased definition of clades. The taxa composition and suggested diagnostic characters are proposed based on the current cladistics analysis, but they may vary with further studies. We 
indicate the uniquely derived ( $\mathrm{ci}=1$ ) and unambiguous characters with an * and we quote other significant characters, i.e. the unambiguous characters with a ci value superior or equal to 0.5 .

Neodipnoi Agnolin, 2010. New definition

Diagnosis: The clade including all taxa more closely related to Lepidosiren, Neoceratodus, Gnathorhiza, Uronemus and Conchopoma than to Ctenodus and Sagenodus. Characters: skull roof shows fusion or loss of bones*, snout has no separate rostral bones*, an ascending pterygopalatine process is present*, gular bone absent*, periorbital bones form an incomplete ring (with a reversion in the crown group), and tooth plate narrow (reversion in Ceratodus). However, the ascending pterygopalatine process and its articulation with the bones of the skull roof in Neoceratodus differs from the equivalent structure in Lepidosiren, and most Devonian lungfish had a thickened area between the upper jaw bone and the skull roof.

Included taxa: Ceratodontoidei, Uronemus, Conchopoma

Suborder Ceratodontoidei Nikolski, 1954

Emended diagnosis: The clade including all taxa more closely related to Lepidosiren, Neoceratodus and Gnathorhiza than to Uronemus, Conchopoma and Sagenodus.

Characters: the EQ or equivalent bone is single*, the lateral series of skull ossifications has two bones or less*, the sensory line canals are superficial*, and no separate bone $\mathrm{F}$ between EQ (independently acquired in Chirodipterus).

Included taxa: Lepidosirenidae, Gnathorhizidae, Ptychoceratodus, Gosfordia, Ceratodus, Neoceratodontidae, Ferganoceratodus, Paraceratodus

Family Lepidosirenidae Bonaparte, 1841

Emended diagnosis: The clade including all taxa more closely related to Lepidosiren than to Gnathorhiza, Neoceratodus, Ferganoceratodus and Sagenodus. Characters: Anterior end of the parasphenoid has a vacuity*, gap between lower jaw bones is absent*, tongue (hyoid) process has no hyoid process*, no splenial and postsplenial*, posterior calvarial bones 
attenuated (independently acquired in neoceratodontids), calvarial bones extravasated (independently acquired in Mioceratodus), mediolateral bones not marked by sensory lines (independently acquired in Mioceratodus), posterior bones not marked by sensory lines (independently acquired in Mioceratodus).

Included genera: Lepidosiren, Protopterus

Family Gnathorhizidae Miles, 1977

Emended diagnosis: The clade including all taxa more closely related to Gnathorhiza than to Lepidosiren, Neoceratodus, Ferganoceratodus and Sagenodus. Characters: Cusps on last ridge compressed laterally, in line with ridge*, and upper dentition separated (a unique reversion).

Included genera: Gnathorhiza, Persephonichthys

Family Neoceratodontidae Miles, 1977

Emended diagnosis: The clade including all taxa more closely related to Neoceratodus than to Lepidosiren, Gnathorhiza, Ferganoceratodus and Sagenodus. Characters: a posterior heel on tooth plate is present*, posterior calvarial bones attenuated (independently acquired in lepidosirenids), prearticular sulcus double (independently acquired in Ptychoceratodus and Gosfordia), and ridge origin anterior (independently acquired in Ptychoceratodus and Gosfordia).

Included genera: Neoceratodus, Mioceratodus

\section{Conclusions}

The major novelty of the phylogeny obtained with the new set of characters discussed in this study is the close relationships between the gnathorhizodontids and the lepidosirenids. This connection was suggested a long time ago, but was generally dismissed by recent authors and it has never been demonstrated on the basis of a cladistics analysis. The evidence supporting this relationship is still weak, but we regard it as a working hypothesis for future 
analyses. One consequence of this relationship is that the split between both extant lineages of lungfishes is pushed back into the past, in the Early Permian, making the evolutionary distinctiveness of the Australian lungfish still higher than previously calculated. The topologies of the common taxa between the available published phylogenies of Palaeozoic genera and our post-Devonian phylogeny did not match perfectly, which forced us to exclude Ctenodus from the taxic diversity and body size analyses. The persisting discrepancy between Devonian and post-Devonian datasets is due to the major changes that occurred in the cranial anatomy and in the alteration of the nature of the fossil record between both sets. The definition of a series of characters relevant for all lungfishes is still pending and constitutes the next challenging task for a better understanding of the phylogenetic relationships within the whole clade. The Carboniferous and Permian taxa play a pivotal role in this task.

Computed taxic diversity shows two successive similar trends, which occurred first in marine then in freshwater environments. The marine peak of diversity occurred in the middle Devonian and is followed by a regular decrease throughout the Carboniferous (Romer's Gap appears to be a preservational artefact) and the second freshwater peak of diversity occurred in the Early Permian and is followed by a regular decrease up to the present. Environmental transfers from marine to freshwaters occurred twice during the evolutionary history of lungfishes (or maybe three times depending on the phylogenetic position of Conchopoma). One occurred in the Middle Devonian, approximately at the same time as the terrestrialisation of tetrapodomorphs, and the second one, at the origin of the extant freshwater lineages, occurred in the Late Carboniferous. An intriguing result obtained in this study, still compromised by biases caused by the ontogenetic status of some specimens, is that most of the major body size decreases occurred during the marine phase of the evolutionary history of the group, to the contrary of what is generally observed in the marine realm. In continental environments, a general trend towards larger body size is observed in several lineages.

\section{Acknowledgments}

This paper is a contribution to the project "Fish Response to Long-Term Global Changes", supported by the Swiss National Science Foundation (200021-140827). Specimens of the Australian lungfish were collected with the permission of the University of Queensland Animal Ethics Committee, approval number CMM/013/03/ARC and the Queensland Fisheries Management Authority, permit number PRM03012K. We thank the reviewers for their constructive comments. 


\section{References}

Agnolin, F., 2010. A new species of the genus Atlantoceratodus (Dipnoiformes:

Ceratodontidei) from the uppermost Cretaceous of Patagonia and brief overview of fossil dipnoans from the Cretaceous and Paleogene of South America. Brazilian Geographical Journal: Geosciences and Humanities Research Medium 1, 162-210.

Bemis, W.E., 1987. Feeding systems of living Dipnoi; Anatomy and Function. Journal of Morphology Supplement 1, 249-275.

Berman, D., 1968. Lungfish from the Lueders Formation (Lower Permian, Texas) and the Gnathorhiza-lepidosirenid ancestry questioned. Journal of Paleontology 42, 827-835.

Berman, D.S., 1976. Cranial morphology of the Lower Permian lungfish Gnathorhiza (Osteichthyes: Dipnoi). Journal of Paleontology 60, 1020-1033.

Bonaparte, C.L., 1841. A new systematic arrangement of vertebrate animals. Transactions of the Linnean Society 18, 247-303.

Boyd, C.A., Cleland, T.P., Marrero, N.L., Clarke, J.A., 2011. Exploring the effects of phylogenetic uncertainty and consensus trees on stratigraphic consistency scores: a new program and a standardized method. Cladistics 27, 52-60.

Callen, R.A., Tedford, R.H., 1976. New late Cainozoic rock units and depositional environments, Lake Frome area, South Australia. Transactions of the Royal Society of South Australia 100, 125-167.

Campbell, K.S.W., Barwick, R.E., 1990. Functional Complexes and Evolution Without Parsimony. Paleobiology, 16, 143-169.

Carlson, K.J., 1968., The Skull Morphology and Estivation Burrows of the Permian Lungfish, Gnathorhiza serrata. The Journal of Geology 76, 641-663.

Cavin, L., Kemp, A., 2011. The impact of fossils on the evolutionary distinctiveness and conservation status of the Australian lungfish. Biological Conservation 144, 3140-3142.

Churcher, C.S., De Iuliis, G., Kleindienst, M.R., 2006., A new genus for the dipnoan species Ceratodus tuberculatus Tabaste, 1963. Geodiversitas 28, 635-647.

Clement, A.M., Long, J.A., 2010. Air-breathing adaptation in a marine Devonian lungfish. Biology Letters, 509-512.

Coates, M. I., Clack, J. A., 1995. Romer's Gap - tetrapod origins and terrestriality. In Arsenault, M. Lelièvre and Janvier P. (Eds) Proceedings of the 7th International Symposium on Lower Vertebrates, Miguasha: Studies on Early Vertebrates. Bulletin du Muséum national d'Histoire naturelle, Paris.17, 373-388. 
Clement, A. M., Long, J. A., Tafforeau, P., Ahlberg, P. E., 2016. The dipnoan buccal pump reconstructed in 3D and implications for air breathing in Devonian lungfishes. Paleobiology 42, 289- 304.

Dalquest, W.W., 1968. Lungfishes from the Permian of Texas. Copeia 1968, 194-197.

Dalquest, W., Kocurko, M.J., Grimes, J.V., 1989. Aspects of the postcranial skeleton of the Lower Permian lungfish, Gnathorhiza. Journal of Paleontology 63, 919-930.

Denison, R.H., 1974. The Structure and Evolution of Teeth in Lungfishes. Fieldiana Geology $33,31-58$.

Foote, M., 2000. Origination and extinction components of taxonomic diversity: Paleozoic and post-Paleozoic dynamics. Paleobiology 26, 578-605.

Forey, P.L., Fortey, R.A., Kenrick, P., Smith, A.B., 2004. Taxonomy and fossils: a critical appraisal. Philosophical Transactions of the Royal Society, London B 359, 639-653.

Gobetz, K., Lucas, S.G., Lerner, A.J., 2006. Lungfish burrows of varying morphology from the Upper Triassic Redonda Formation, Chinle Group, eastern New Mexico. New Mexico Museum of Natural History and Science Bulletin 37, 140-146.

Greenwood, P. H., 1987. The natural history of African lungfishes. Journal of Morphology Supplement 1, 163-179.

Heim, N.N., Knope, M.L., Schaal, E.K., Wang, S.C., Payne, J.L., 2015. Cope's rule in the evolution of marine animals. Nature 347, 867-870.

Holmgren, N., 1949. Contributions to the question of the origins of the tetrapods. Acta Zoologica (Stockholm) 30, 460-484.

Kemp, A., 1992. New cranial remains of neoceratodonts (Osteichthyes: Dipnoi) from the Late Oligocene to Middle Miocene of Northern Australia with comments on generic characters for Cenozoic lungfish. Journal of Vertebrate Paleontology 12, 284-293.

Kemp, A., 1994. Australian Triassic lungfish skulls. Journal of Paleontology 68, 647-654.

Kemp, A., 1998. Skull Structure in Post-Paleozoic Lungfish. Journal of Vertebrate Paleontology 18, 43-63.

Kemp, A., 2001a. Chirodipterus potteri, a new Devonian lungfish from New South Wales, Australia: and the ontogeny of Chirodipterid tooth plates. Journal of Vertebrate Paleontology 20, 665-674.

Kemp, A., 2001b. Petrodentine in derived dipnoan dentitions. Journal of Vertebrate Paleontology 21, 422-437.

Kerr, J. G., 1950. A Naturalist in the Gran Chaco. Cambridge: Cambridge University Press. 
Lison, L., 1941. Recherches sur la structure et l'histogenèse des dents des poissons dipneustes. Archives de Biologie, Paris 52, 279-320.

Long, J.A., 1992. Cranial anatomy of two new Late Devonian Lungfishes (Pisces: Dipnoi) from Mount Howitt, Victoria. Records of the Australian Museum 44, 299-318.

Long, J.A., 1993. Cranial ribs in Devonian lungfishes and the origin of air-breathing. Memoirs of the Australasian Association of Palaeontologists 15, 199-210.

Lloyd, G.T., Wang, S.C., Brusatte, S. L., 2012. Identifying heterogeneity in rates of morphological evolution: discrete character change in the evolution of lungfish (Sarcopterygii: Dipnoi). Evolution 66, 330-348.

Marshall, C.R., 1986. Lungfish: phylogeny and parsimony, in: Bemis, E., Burggren, W.W., Kemp, N.E. (Eds.), The Biology and Evolution of lungfishes, pp. 151-162.

Marshall, C.R., 1988. A large, well preserved specimen of the Middle Pennsylvanian lungfish Conchopoma edesi (Osteichthyes: Dipnoi) from Mazon Creek, Illinois, U.S.A. Journal of Vertebrate Paleontology 8, 383-394.

Marshall, M.S., Rogers, R.R., 2012 Lungfish burrows from the upper Cretaceous Maevarano formation, Mahajanga Basin, northwestern Madagascar. Palaios 27, 857-866.

McCahon, T.J., Miller, K.B., 2015. Environmental significance of lungfish burrows (Gnathorhiza) within Lower Permian (Wolfcampian) paleosols of the US midcontinent. Palaeogeography, Palaeoclimatology, Palaeoecology 435, 1-12.

Miles, R.S., 1977. Dipnoan (lungfish) skulls and the relationships of the group: a study based on new species from the Devonian of Australia. Zoological Journal of the Linnean Society $61,1-328$.

Nikolski, G. W. 1954. Castnaja ichtiologija. Sovetskaja Nauka, Moscow. [Russian]

Olson, E.C., 1951. Fauna of Upper Vale and Choza: 1-5. Fieldiana, Geol. 10, 89-128.

Olson, E.C., Daly, E., 1972. Notes on Gnathorhiza (Osteichthyes, Dipnoi). Journal of Paleontology 46, 371-376.

Orsulak, M., Simpson, E., Wolf, H.L., Simpson, W., Tindall, S., Bernard, J., Jenesky, T., 2007. A lungfish burrow in Late Cretaceous upper capping sandstone member of the Wahweap Formation Cockscomb area, Grand Staircase-Escalante National Monument, Utah, Abstracts with Programs - Geological Society of America, p. 43.

Paradis, E., Claude, J., Strimmer, K., 2004. APE: analyses of phylogenetics and evolution in R language. Bioinformatics 20, 289-290. 
Pardo, J.D., Huttenlocker, A.K., Small, B.J., 2014. An Exceptionally Preserved Transitional Lungfish from the Lower Permian of Nebraska, USA, and the Origin of Modern Lungfishes. PLoS ONE 9, e108542.

Pol, D., Norell, M.A., 2001. Comments on the Manhattan stratigraphic measure. Cladistics $17,285-289$.

Pol, D., Norell, M.A., 2006. Uncertainty in the age of fossils and the stratigraphic fit to phylogenies. Systematic Biology 55, 512-521.

Pol, D., Norell, M.A., Siddall, M.E., 2004. Measures of stratigraphic fit to phylogeny and their sensitivity to tree size, tree shape, and scale. Cladistics 20, 64-75.

Revell, L.J., 2012. phytools: an R package for phylogenetic comparative biology (and other things). Methods in Ecology and Evolution 3, 217-223.

Romer, A.S., Olson, E.C., 1954. Aestivation in a Permian lungfish. Breviora, Museum of Comparative Zoology 30, 1-8.

Romer, A.S., Smith, H.J., 1934. American Carboniferous Dipnoans. The Journal of Geology 42, 700-719.

Schultze, H.-P., 1975. Die Lungenfisch-Gattung Conchopoma (Pisces, Dipnoi). Senckenbergiana lethaea 56, 191-231.

Schultze, H.-P., 1985. Marine to onshore vertebrates in the Lower Permian of Kansas and their paleoenvironmental implications. The University of Kansas. Paleontological Contributions 113, 1-18.

Schultze, H.-P., 1992. A new longheaded dipnoan (Osteichthyes) from the middle Devonian of Iowa, USA. Journal of Vertebrate Paleontology 12, 42-58.

Schultze, H.-P., 2004. Mesozoic sarcopterygians, in: Arratia, G., Tintori, A. (Eds.), Mesozoic fishes 3 - systematics, paleoenvironments and biodiverity. Verlag Dr Friedrich Pfeil, München, pp. 463-492.

Schultze, H.-P., Chorn, J., 1997. The Permo-Carboniferous genus Sagenodus and the beginning of modern lungfish. Contributions to Zoology 67, 9-70.

Schultze, H.-P., Marshall, C.R., 1993. Contrasting the use of functional complexes and isolated characters in lungfish evolution. Memoirs - Association of the Australasian Paleontologists 15, 211-224.

Sharp, E.L., Clack, J.A., 2013. A review of the Carboniferous lungfish genus Ctenodus Agassiz, 1838 from the United Kingdom, with new data from an articulated specimen of Ctenodus interruptus Barkas, 1869. Earth and Environmental Science Transactions of the Royal Society of Edinburgh, 104, 169-204. 
Siddall, M.E., 1998. Stratigraphic fit to phylogenies: a proposed solution. Cladistics 14, 201208.

Smith, M.M., Smithson, T.R., Campbell, K.S.W., 1987. The Relationships of Uronemus: A Carboniferous Dipnoan with Highly Modified Tooth Plates. Philosophical Transactions of the Royal Society of London, Series B, Biological Sciences 317, 299-327.

Smithson, T.R., Richards, K.R., Clack, J.A., 2015. Lungfish diversity in Romer's Gap: reaction to the end-Devonian extinction. Palaeontology 59, 29-44.

Stromer, E., 1910. Ueber das Gebiss der Lepidosirenidae und die Verbrietung tertiarer und mesozoischer Lungenfische. Festschr. Z. 60. Geburtstag Richard Hertwigs 2, 613-624.

Stromer, E., 1938. Die Wustenfisch Ceratodus, Ag. 1833 und seine mezo- und kanozoischen Verwandten. Neues Jahrbuch für Mineralogie und Geologie 80, 248-263.

Skrzycki , P., 2016. The westernmost occurrence of Gnathorhiza in the Triassic, with a discussion of the stratigraphic and palaeogeographic distribution of the genus. Fossil Record 19, 17-29.

Surlyk, F., Milàn, J., Noe-Nygaard, N., 2008. Dinosaur tracks and possible lungfish aestivation burrows in a shallow coastal lake; lowermost Cretaceous, Bornholm, Denmark. Palaeogeography, Palaeoclimatology, Palaeoecology 267, 292-304.

Swofford, D.L., 2001. PAUP*: phylogenetic analysis using parsimony and other methods (software). Sinauer Associates, Sunderland .

Wills, M.A., 1999. Congruence between phylogeny and stratigraphy: randomization tests and the gap excess ratio. Systematic Biology 48, 559-580. 


\section{Caption}

Figure 1

Schematic reconstructions of the skull and body of selected lungfish genera redrawn from various sources, with labelling of some characters used in the phylogenetic analysis. Characters in blue represent plesiomorphic condition and in red and green represent apomorphic condition. Note that the reconstruction of Gnathorhiza is tentative and based on information from Dalquest (1989).

Figure 2

Single most parsimonious tree $(154$ steps, $\mathrm{CI}=0.5325, \mathrm{RI}=0.6742)$. In brackets: bootstrap values / Bremer indexes. Squares indicate uniquely derived characters (black for the unambiguous, white for the ambiguous.)

\section{Figure 3}

A, Time-scaled composite tree including pre-Devonian (black clades) and post-Devonian (red clade) taxa with mapped fossil record and ghost ranges. B, Four computed phylogenetic diversity estimates (blue curves) with corresponding phylogenetic diversity range (blueshaded area) plotted against observed data. C, Ranges of per capita origination and extinction rates based on computed phylogenetic diversities. Blue-shaded areas show the range of possible rate values according to the four phylogenetic diversity estimates. Accolades indicate the range of timing for a single diversity event.

Figure 4

Time-scaled composite phylogenetic tree with mapped ancestral environment distribution and body size. Numbers in blue and red indicate negative and positive body size shifts, respectively. Numbers in bold correspond to major shifts.

\section{Table 1}

Character - Taxon matrix 
Dipterus

Chirodipterus

- Sagenodus

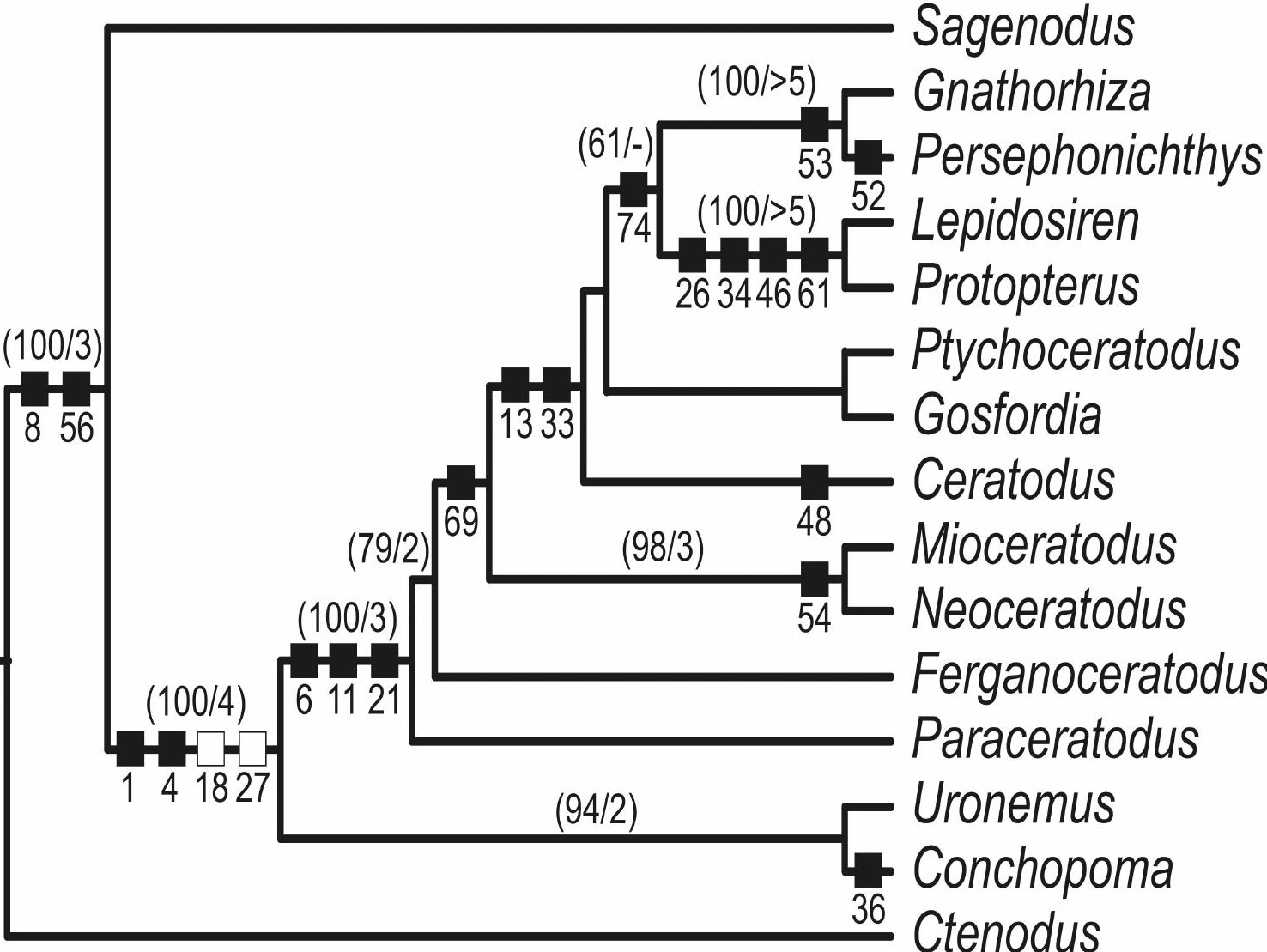




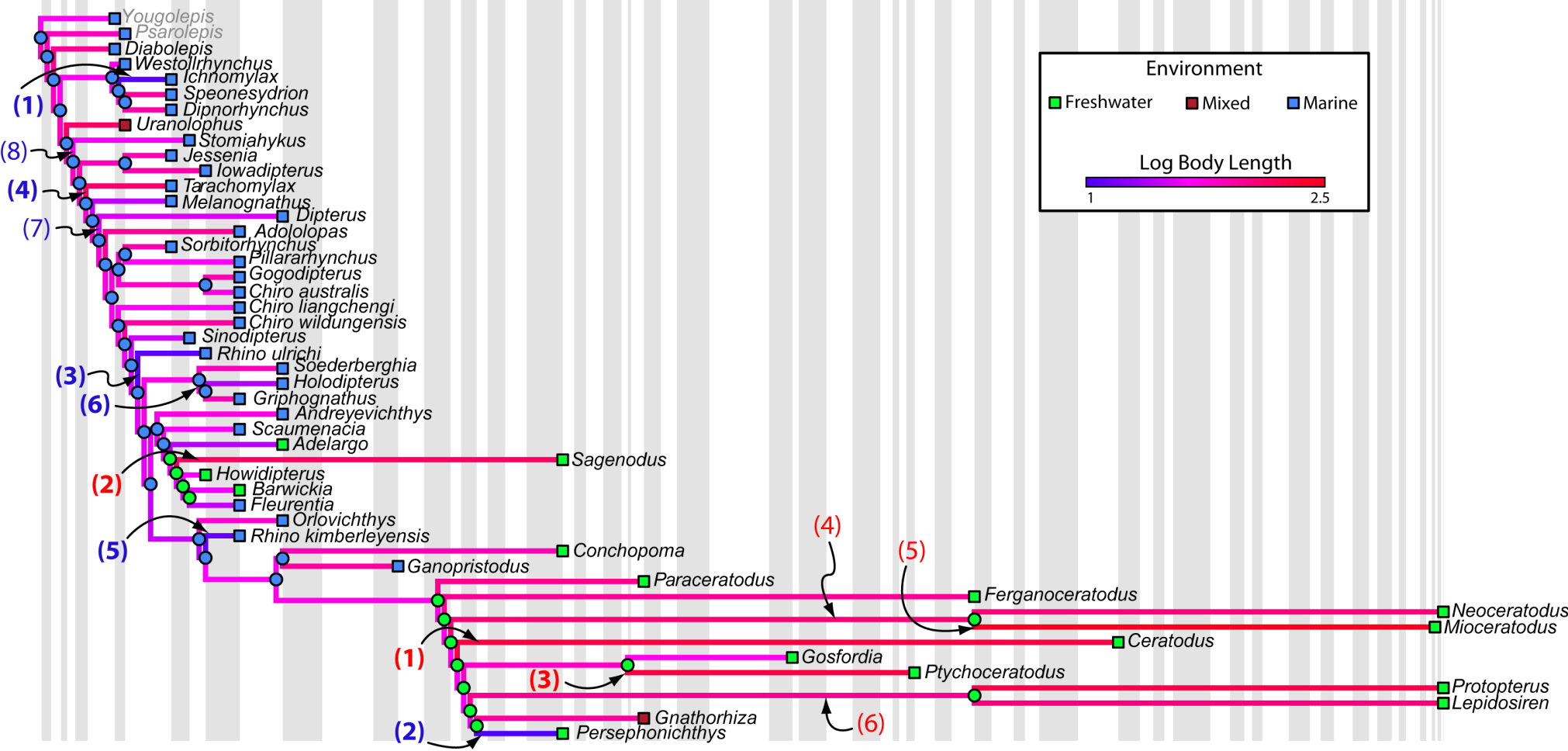

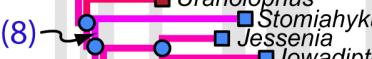

(4)

(7) $\begin{gathered}\text { Sorbitorhydololopas } \\ \text { Pillararhynchus }\end{gathered}$

(3) 乙9

(6) 07 Griphognathus $\square$ Barwickia

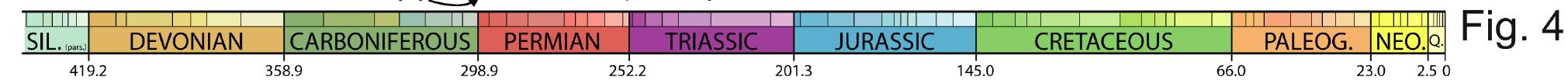

